\section{Military Technical College Kobry El-Kobbah, Cairo, Egypt}

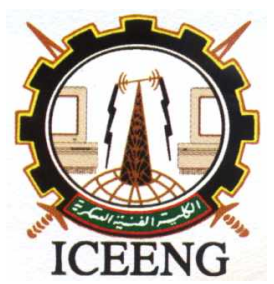

\author{
$6^{\text {th }}$ International Conference \\ on Electrical Engineering \\ ICEENG 2008
}

\title{
OPTIMAL BASED DEMAND SIDE MANAGEMENT FORMULATION
}

\begin{abstract}
By
H. A. ATTIA *

\section{Abstract:}

Utilities around the world are now considering Demand Side Management (DSM) in their strategic planning. The costs of constructing and operating a new capacity generation unit are increasing everyday, which force the utilities to search for another alternative without any additional constraints on customers comfort level or quality of delivered product. DSM encompasses a broad range of utility initiated activities to encourage end users to willingly modify their electricity consumption without any impact on service quality or customer satisfaction. It was found that an objective function reflecting the user electricity expenses did widely serve the best for both the electric utility as well as the end user. From a utility point of view, benefits are meterized as freed capacity, deferred investment or increased revenues. Other developed target objective functions such as maximizing the load factor or the utility revenues did serve to achieve its targets but without much impact on end user electricity expenses or even increased ones. From the customers point of view, the objective is to decrease the amount of electricity bill. The main target of this paper is to derive a mathematical formulation for different DSM programs that can be designed subject to the different problems that may face the utilities, operators and engineers.
\end{abstract}

\section{Keywords:}

Demand Side Management, Optimal Formulation, Objective Function, Constraints, Load Factor, Revenue

* Electrical Power and Machines Department, Faculty of Engineering, Cairo University, Giza, Egypt 


\section{Introduction}

The scope of the DSM programs is the planning, development and implementing of programs whose objective is to shape actively the daily and seasonal electric load profiles of customers to realize or achieve better overall system utilization.

DSM activity has grown and matured over the past decades. Many utilities have implemented DSM programs on a routine basis and more utilities are considering DSM as a part of their resource planning process.

The benefits from applying DSM programs are mutual for both the customer and the utility; utilities will have better utilization of the available system capacity. For customers, the amount of monthly electric bill will be decreased besides the improvement in the electrical service quality.

At the heart of the DSM programs, there is a series of measures intended to encourage specific groups of customers to modify their energy usage patterns in a manner consistent with the utility's DSM objectives while maintaining or enhancing customer satisfaction.

Different utilities have different programs to be applied on their customers. These programs are different according to the number of participated customers in the program, nature of the targeted load type (commercial, industrial or residential), the revenue from each program and the level of customers satisfaction or reaction towards similar applied programs. These programs can be augmented in five steps: DSM targets, financial and feasibility study, designing of effective programs, program implementation and evaluation.

\section{DSM PROGRAMS}

In this section, the different DSM. programs will be briefly explained to clarify the main objective of the program and the changes made on a typical load curve after applying this program. DSM. program is used to control the load profile indirectly in order to achieve the utility and/or customer objectives. These objectives are:

$\ddot{y}$ Improving the system load factor,

$\ddot{y}$ Reducing customer monthly electricity bill.

By achieving the previous objectives, the utility would get the maximum possible energy from the installed units, thus maximizing the total profit and minimizing the average cost per KWh. These programs are [1]: 


\subsection{Valley Filling:}

In this program, the main objective is to increase the demand during the off peak periods while having the same load peak. This could be achieved by encouraging the consumers to increase their demand.

\subsection{Load Shifting:}

In this program, it is required to shift part of the demand at the peak period to the off peak periods. This program could be used in case that the installed capacity is not enough during the peak load.

\subsection{Peak Clipping:}

This program is used to decrease the demand during the peak load periods. Also, these loads can't be shifted to the off peak periods.

This could be due to lack of installed capacity during these periods. This program could be achieved be indirectly forcing the consumers to decrease their loads by the use of miniatures on their supply points.

\subsection{Energy Conservation:}

This program is used when it is required to decrease the energy consumption allover the load period. This could be achieved by using high efficiency components.

\subsection{Load Building:}

This program is used when it is required to increase the energy consumption. This could be very beneficial in case of surplus capacity. This is because the average cost per KWh will decrease.

It may be noted that peak clipping, load shifting and energy conservation techniques are considered as new resources that can help the utility to meet the increasing demand of its customers. Loads building and valley filling are economic efficiency options for power systems with long term exceptions of surplus power. 


\section{MEANS OF IMPLEMENTING DSM TECHNIQUES}

Means of implementing DSM techniques can be categorized into [2-4]:

\subsection{Direct Load Control}

It is an obligation way by which the utility can modify customers load pattern. It can be applied by switching off the power supply on specific category of customers at specific time interval, or force the customers not to use a specific type of electrical load at a specific time interval.

\subsection{Indirect Load Control}

It is an optimal way by which the utility can change the customers load pattern by using special methods such as :

- Time of use rates.

- Efficient end use technologies.

- Thermal energy storage.

- Electrification technologies.

The more commonly used methods are the electric tariff system and time of use rates.

Figure 1 illustrates the classic taxonomy of load shape objectives.

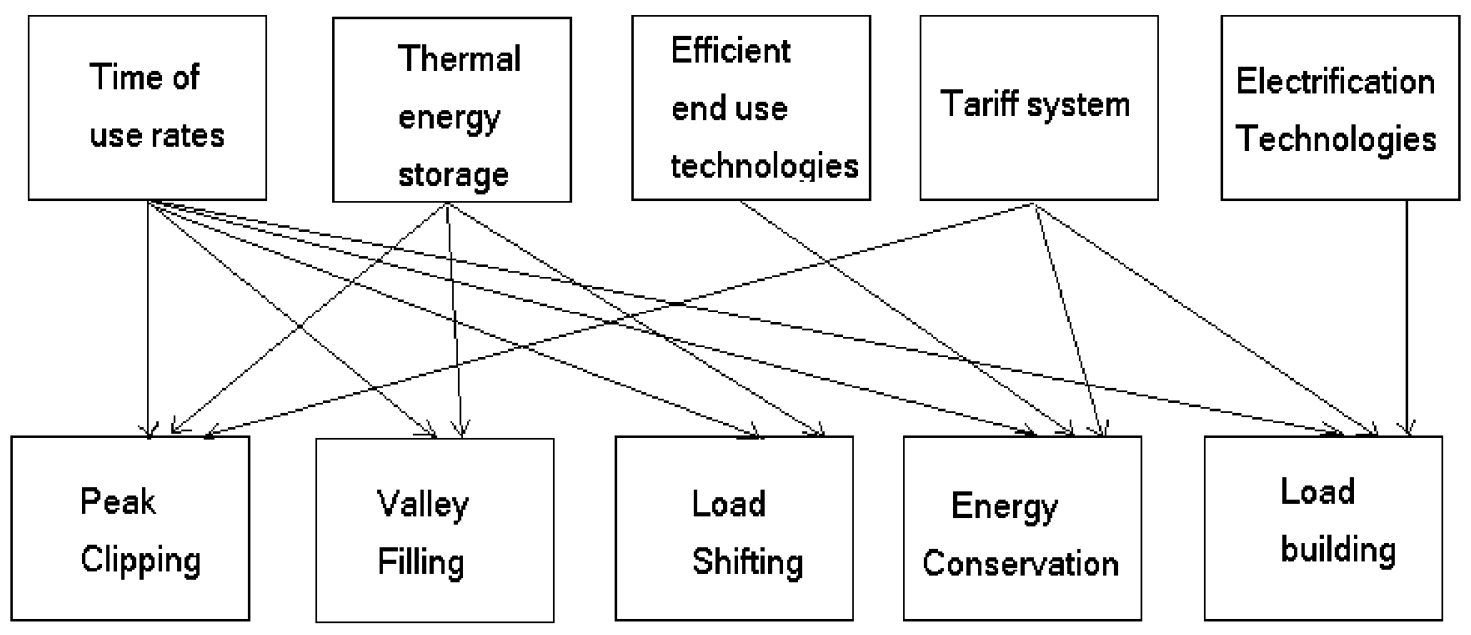

Fig. 1 The classic taxonomy of load shape objectives.

\section{Optimal Based formulation for DSM programs}

DSM has a major role of utility planning and operation. In this section, an optimal based formulation is developed to simulate the implementation process of the DSM program to assess its technical and financial impacts for both utility and users. The objective function is formulated either to control the use of the supply side resources 
subject to end user demand for power and energy without loss of production or comfort, or to improve system performance by increasing load factor and enhance the customer service quality.

The mathematical construction model for any optimization problem is generally determined by clarifying the following questions $[5,6]$ :

i. What does the model seek to determine?

ii. What are the objectives (goals) needed to be achieved to determine the best solution?

iii. What are the variables of the problem?

iv. What constraints must be imposed on variables to simulate properly actual variables?

The mathematical formulation of the DSM techniques as an optimization problem is given. Two sorts for the objective function are contributed, either to maximize the system load factor for the utility, or to minimize the total cost of the bill for the customer. While there exist two sorts for the objective function for the five DSM techniques, the imposed constraints on the demand type at different time intervals (control variables) differ from a technique to another and depend, also, on the load peculiarities and the power system.

DSM programs seek to optimize either of the following two objective functions :

$$
\begin{aligned}
& \text { Max.L.F. }=\left[\left[\sum_{i=1}^{N} \sum_{j=1}^{J} P_{(i, j)} \times t_{(j)}\right] / \sum_{j=1}^{J} t_{(j)}\right] \\
& / \sum_{i=1}^{N} P_{(i, k)} \\
& \text { Or: Max.L.F. }=\left[\left[\sum_{j=1}^{J} P_{T O(j)} \times t_{(j)}\right] / \sum_{j=1}^{J} t_{(j)}\right] / P_{T O(K)} \\
& \text { Min. } C=\left[\sum_{i=1}^{N} \sum_{j=1}^{J} P_{(i, j)} \times t_{(j)} \times c e_{(i, j)}\right] \\
& +\left[\sum_{i=1}^{N} \sum_{j=1}^{J} P_{(i, j)} \times c d_{(i, j)}\right]
\end{aligned}
$$

Where,

L.F : $\quad$ is the system load factor. 
$P_{(i, j))}: \quad$ is the demand of load type $\mathrm{i}$ at time interval number $\mathrm{j}$.

$\mathrm{N}: \quad$ is the total number of load demand types.

$\mathrm{J}$ : $\quad$ is the total number of time intervals.

$P_{T O(j)}: \quad$ is the total demand for all the loads types from $j=1$ to $j=J$ over the time interval number $\mathrm{j}$.

$\mathrm{k}$ : $\quad$ is the number of time interval at which the maximum demand for all the load types numbers from $\mathrm{i}=1, \mathrm{~N}$ over all the time duration from $\mathrm{j}=1, \mathrm{~J}$ occurs.

$\mathrm{C}$ : $\quad$ is the total cost of the electrical demand and energy consumption.

$\mathrm{ce}_{(\mathrm{i}, \mathrm{j})}: \quad$ is the cost of energy for load type $\mathrm{i}$ at time interval number $\mathrm{j}$.

$\left.\operatorname{cd}_{(i, j)}\right)$ is the cost of demand for load type $i$ at time interval number $j$.

In the following, the different DSM techniques including the related objective function and constraints as an optimization problem are presented. The description of the method and effect on load shape in addition to means of implementation are also given.

\subsection{Valley Filling}

Program description and effect on load shape: It entails building of off-peak loads. This is often the case when there is under utilized capacity that can operate on low cost fuels. The net effect is an increase in total energy consumption, while the peak demand is kept fixed (Fig. 2), consequently, the load factor will be improved.

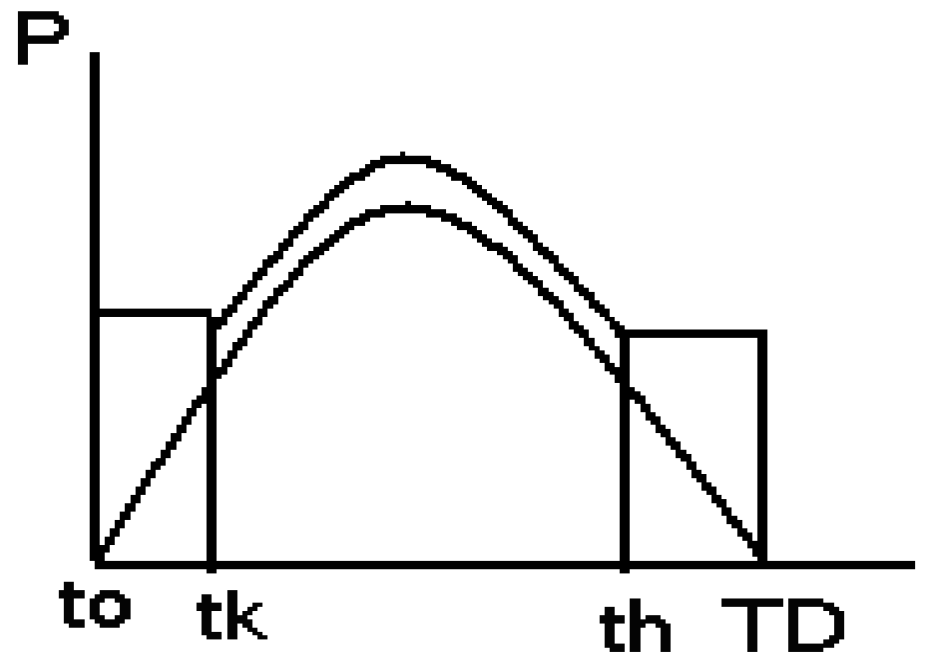

Fig. 2 Load demand control to achieve valley filling DSM program

Means of implementation: This can be achieved by creation of new off-peak electric loads such as charging of electric cars and thermal energy storage.

Objective function: The objective function is formulated to maximize the system load factor as follows: 


$$
\begin{gathered}
\text { Max.L.F. }=\left[\left[\sum_{i=1}^{N} \sum_{j=1}^{J} P_{(i, j)} \times t_{(j)}\right] / \sum_{j=1}^{J} t_{(j)}\right] / \sum_{i=1}^{N} P_{(i, k)} \\
\text { Or: } \operatorname{Max.L.F.}=\left[\left[\sum_{j=1}^{J} P_{T O(j)} \times t_{(j)}\right] / \sum_{j=1}^{J} t_{(j)}\right] / P_{T O(K)}
\end{gathered}
$$

Subject to :

Equality constraint:

$$
\text { Pnew }(i, j)=\text { Pold }(i, j) \forall t \mathrm{k} \rightarrow t h
$$

Inequality constraints:

$$
\begin{gathered}
\text { Pnew }(i, j) \geq \text { Pold }(i, j) \forall \text { to } \rightarrow \text { tk, th } \rightarrow T D \\
\text { Pnew }(i, j) \leq P(\text { value }) \forall \text { to } \rightarrow \text { tk }, \text { th } \rightarrow T D
\end{gathered}
$$

Where:

$\mathrm{P}_{\text {new(i,j): }}$ : is the demand of load type $\mathrm{i}$ at time interval $\mathrm{j}$ after applying DSM technique.

$\mathrm{P}_{\text {old }(\mathrm{i}, \mathrm{j})}$ : is the demand of load type $\mathrm{i}$ at time interval $\mathrm{j}$ before applying DSM technique

$\mathrm{P}_{\text {(value): }}$ is an extreme limiting value given by the planner for load demand after applying DSM program.

$\mathrm{k}$ : $\quad$ is the time interval at which the total demand of all load types $\mathrm{P}_{\mathrm{To}(\mathrm{k})}$ is maximum.

$\mathrm{P}_{\mathrm{To}(\mathrm{k})}$ : is the max. demand for all the load types over all time intervals.

$$
\text { PTo }(k)>P T o(j) \forall j=1, \ldots . ., J ; j \neq k
$$

$\mathrm{TD}: \quad$ is the sum of all time intervals; $\mathrm{TD}=\sum_{j=1}^{J} t_{(j)}$

The $P_{\text {new }(i, j)}$ is not permitted to increase the $P_{(v a l u e)}$ which is an extreme limiting value given by the planner.

\subsection{Load Shifting}

Program description and effect on load shape: It involves shifting loads from on-peak to off-peak periods (Fig. 3). The net effect is a decrease in peak demand, but no change in the total energy consumption. This effectively, improves the system load factor and decreases the cost of the electricity bill. 
Means of implementation: This can be achieved by time of use rates and/or use of storage devices that shift the timing of conventional electric appliances operation.

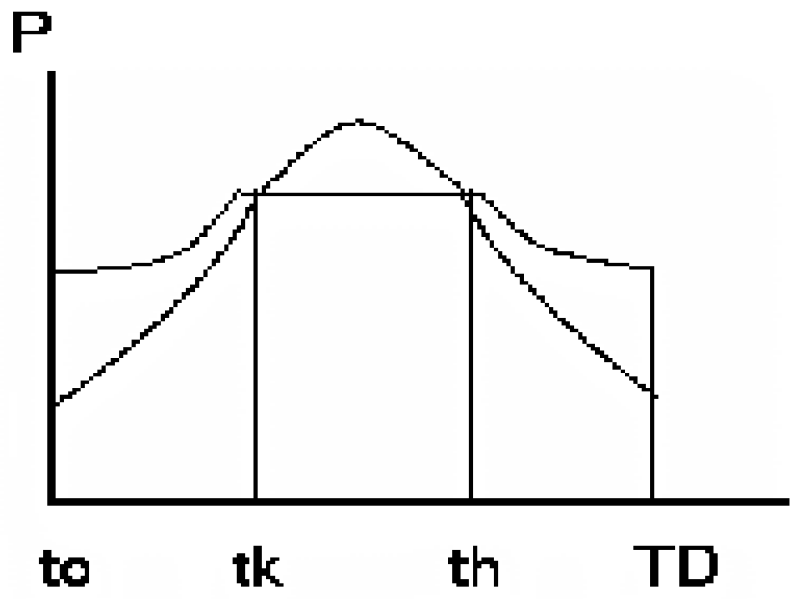

Fig. 3 Load demand control to achieve load shifting DSM program

Objective function: The objective function is formulated either to maximize the system load factor or to minimize the customer electricity bill as follows :

$$
\begin{aligned}
& \text { Max.L.F. }=\left[\left[\sum_{j=1}^{J} P_{T O(j)} \times t_{(j)}\right] / \sum_{j=1}^{J} t_{(j)}\right] / P_{T O(K)} \\
& \text { Min. } \quad C=\left[\sum_{i=1}^{N} \underset{j=1}{\sum^{J}} \quad P_{(i, j)} \times t_{(j)} \times c e_{(i, j)}\right] \\
& +\left[\sum_{i=1}^{N} \sum_{j=1}^{J} \quad P_{(i, j)} \times c d_{(i, j)}\right]
\end{aligned}
$$

Or

Subject to :

- Equality constraint:

$$
\begin{aligned}
& \sum_{i=1}^{N} \sum_{j=1}^{J} \operatorname{Pnew}(i, j) * t(j)=\sum_{i=1}^{N} \sum_{j=1}^{J} \operatorname{Pold}(i, j) * t(j) \\
& \operatorname{Pnew}(i, j)=P(\text { value }) \forall t k \rightarrow t h
\end{aligned}
$$

- Inequality constraints:

$$
\begin{gathered}
\text { Pnew }(i) \geq \operatorname{Pold}(i) \forall t o \rightarrow t k, t h \rightarrow T D \\
\text { Pnew }(i) \leq P(\text { value }) \forall t o \rightarrow t k, t h \rightarrow T D
\end{gathered}
$$




\subsection{Peak Clipping}

Program description and effect on load shape: Peak clipping refers to reduction of utility loads during peak demand periods (Fig. 4). The net effect is a reduction in both demand and total energy consumption. Therefore, The system load factor is improved and, also, the customer electricity bill is decreased.

Means of implementation: Direct utility control on customer appliances or end-use equipment can be carried out to reduce peak demand periods.

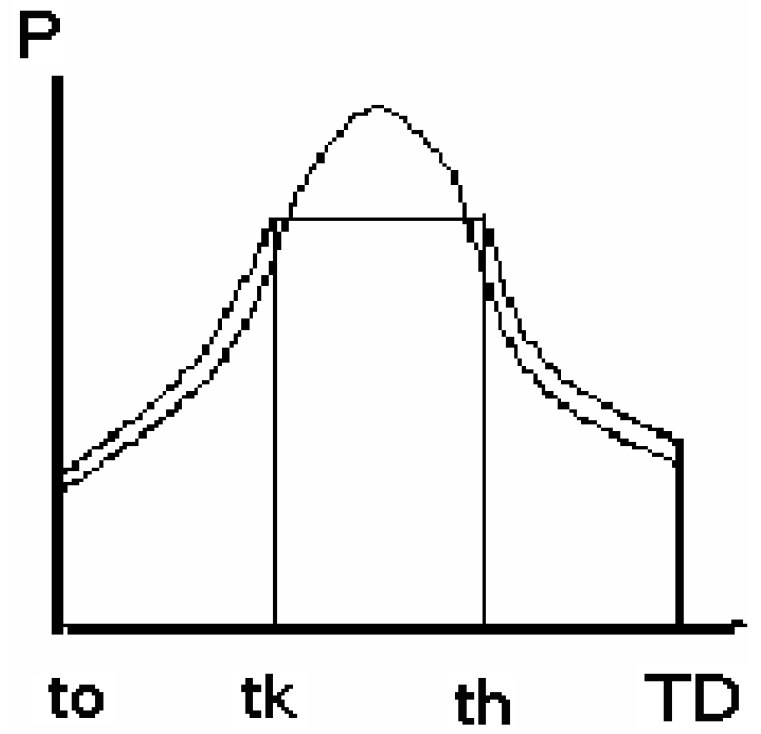

Fig. 4 Load demand control to achieve Peak clipping DSM program.

Objective function : The objective function is formulated either to maximize the system load factor as follows:

$$
\text { Max.L.F. }=\left[\left[\sum_{j=1}^{J} P_{T O(j)} \times t_{(j)}\right] / \sum_{j=1}^{J} t_{(j)}\right] / P_{T O(K)}
$$

Subject to : - Equality constraint :

$$
\operatorname{Pnen}(i)=\operatorname{Pold}(i) \forall t o \rightarrow t k, t h \rightarrow T D
$$

- Inequality constraints:

$$
\begin{gathered}
\text { Pnew }(i) \leq P(\text { value } 1) \forall \text { tk } \rightarrow \text { th } \\
\text { Pnew }(i) \geq P(\text { value } 2) \forall t k \rightarrow \text { th } \\
P(\text { value } 2) \leq P(\text { value } 1)
\end{gathered}
$$

$\mathrm{P}_{\text {(value1) }}$ ' $\mathrm{P}_{\text {(value2) }}$ : are limiting values given by the planner, that depends on the nature of the load and user activity, for load demand after applying DSM program. 


\subsection{Energy Conservation}

Program description and effect on load shape: It refers to reduction in end-use consumption. Both peak demand and total energy consumption are reduced [8,9] (Fig. 5). Means of implementation: Appliances efficiency improvement and weatherization are some examples for energy conservation.

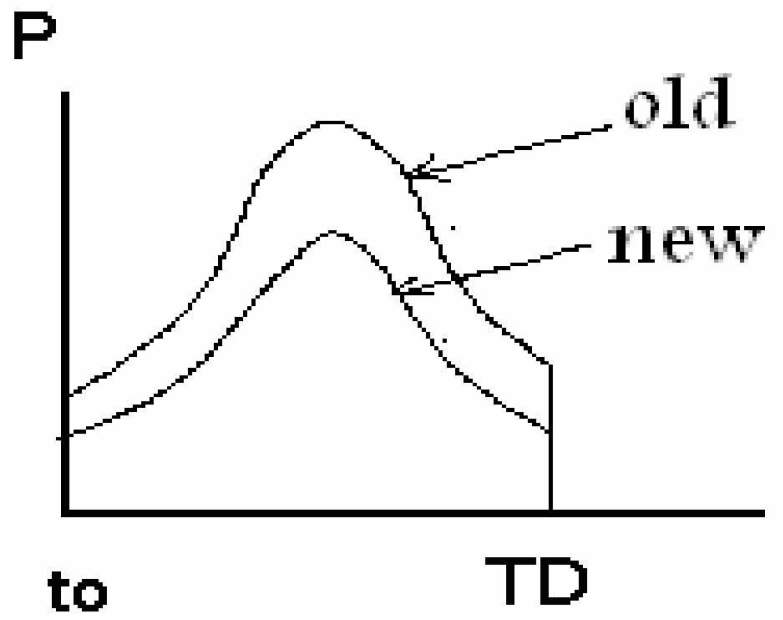

Fig. 5 Load demand control to achieve energy conservation DSM program

Objective function: The objective function is formulated to minimize the cost of the customer electricity bill as follows:

$$
\begin{aligned}
& \text { Min. } \quad C=\left[\sum_{i=1}^{N} \sum_{j=1}^{J} P_{(i, j)} \times t_{(j)} \times c e_{(i, j)}\right] \\
& +\left[\sum_{i=1}^{N} \sum_{j=1}^{J} P_{(i, j)} \times c d_{(i, j)}\right.
\end{aligned}
$$

Subject to : - Inequality constraint

$$
\text { Pnew } \quad(i) \leq P(\text { old }(i)) \forall \text { to } \rightarrow T D
$$

\subsection{Load Building}

Program description and effect on load shape: It refers to an increase in overall sales. The net effect is an increase in both peak demand and total energy consumption (Fig. 6). 


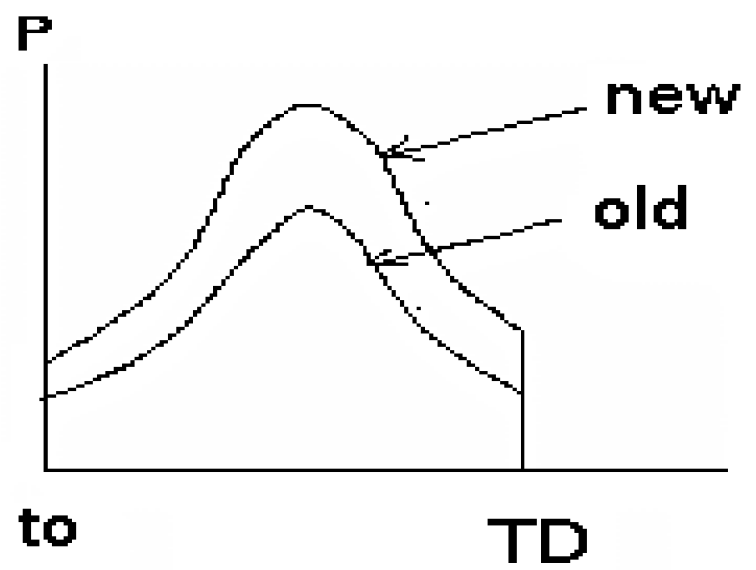

Fig. 6 Load demand control to achieve load building DSM program.

Means of implementation: Load building involves increased market share of loads that can use electric energy instead of fuel. Electric vehicles, industrial heating and electrification may be, also, effective means for load building.

Objective function: The objective function is formulated to maximize utility revenue as follows:

$$
\begin{aligned}
& \text { Max. Revenue }=\left[\sum_{i=1}^{N} \sum_{j=1}^{J} P_{(i, j)} \times t_{(j)} \times c e_{(i, j)}\right] \\
& +\left[\sum_{i=1}^{N} \sum_{j=1}^{J} P_{(i, j)} \times c d_{(i, j)}\right]
\end{aligned}
$$

Subject to : - Inequality constraints:

$$
\text { Pnew } \quad(i) \geq P(\text { old }(i)) \forall \text { to } \rightarrow T D
$$

\section{SOLUTION TOOLS}

After the different DSM programs have been formulated in the form of optimization problems, these problems have to be solved utilizing efficient mathematical tools. Two softwares were utilized to solve the optimization problem. The first was the solver which is a MS excel based tool used to solve optimization problems. The main screen of the solver is shown in Fig. 7. In the solver main screen, the objective function is written in the target cell where the constraints and variables to be optimized are written in the changing cells. 


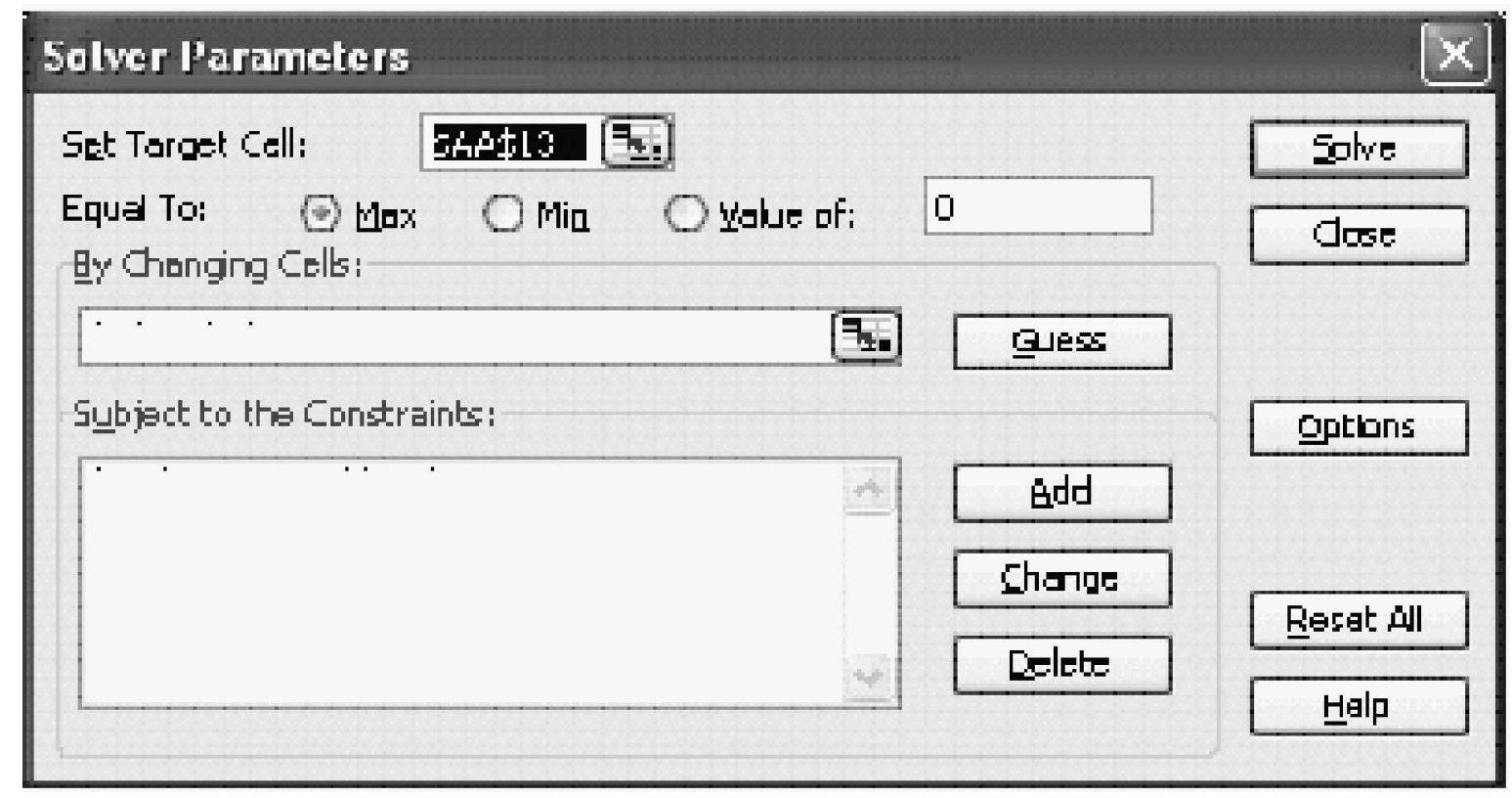

Fig. 7 Solver main screen

The second tool was LINGO optimization program. LINGO program is a simple tool for utilizing the power of linear and nonlinear optimization to formulate large problems briefly, solve them, and analyze the solution. The objective function and constraints including the problem variables are fed to the program. The goal of optimization is to find the values of a model's variables that generate the best value for the objective function, subject to any limiting conditions placed on the variables. No confliction was found between the results of the two tools.

\section{CASE STUDY}

An industrial plant daily load curve was utilized to clarify the benefits of DSM programs and to substantiate the validity and powerful of the introduced formulations. The original load curve before applying DSM programs is shown in Fig. 7. As an example, the results of applying the load shifting and the peak clipping techniques are only shown. Figure 8 shows the load curve before and after applying load shifting DSM program, while Fig. 9 shows the load curve before and after applying peak clipping DSM program. The salient results of the two applications are shown in Table 1. 


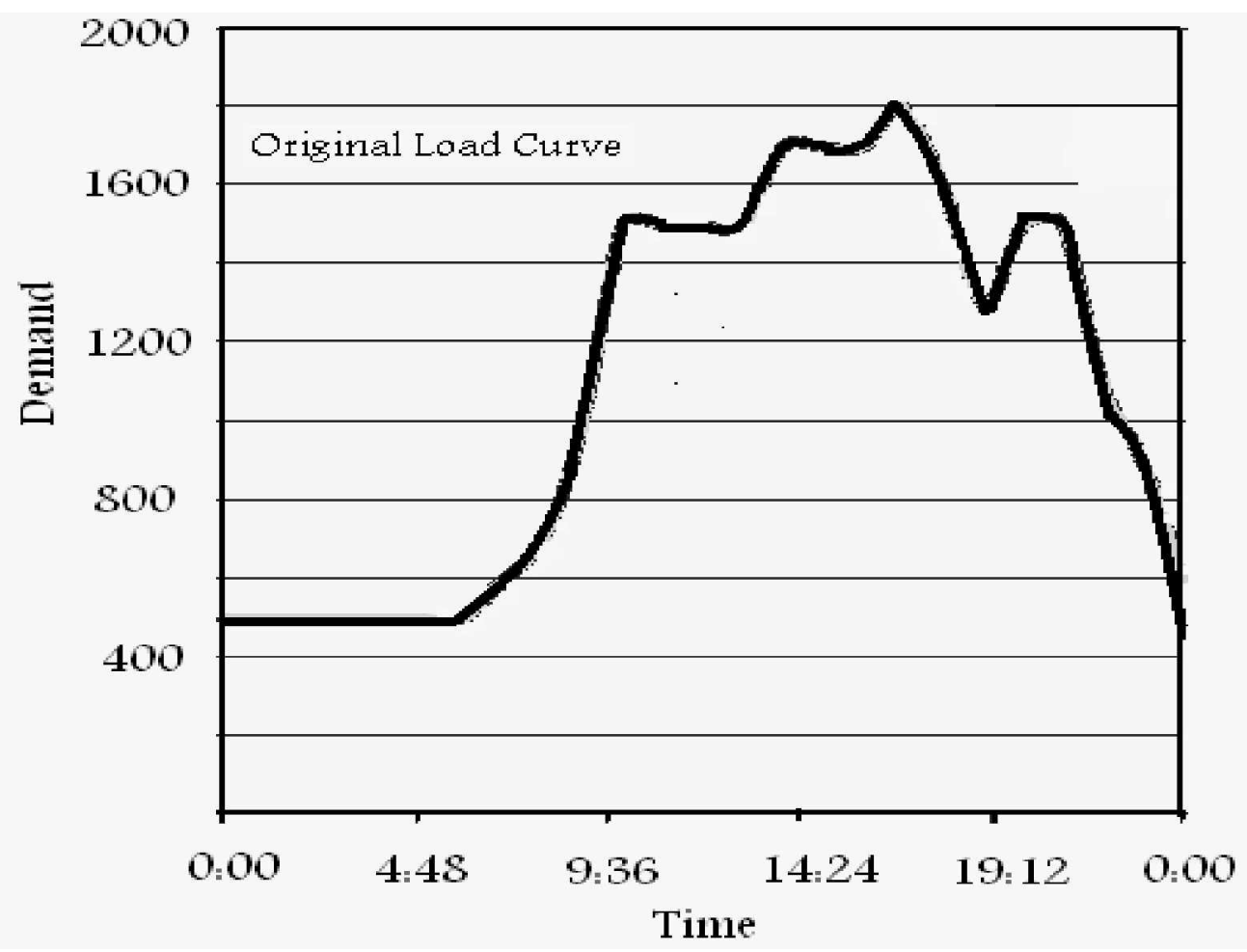

Fig. 7 Load curve before applying DSM program.

The load factor has improved from 0.618 to 0.856 for load shifting program, and to 0.774 for peak clipping program. Besides, the monthly customer bill has decreased by about $2.65 \%$ for load shifting program and $18.09 \%$ for peak clipping program. The demand cost was considered to be 87.6 L.E./KW while the energy cost was considered to be 0.1535 L.E./KWH. In the two applications, the objective function was formulated to maximize the system load factor. 


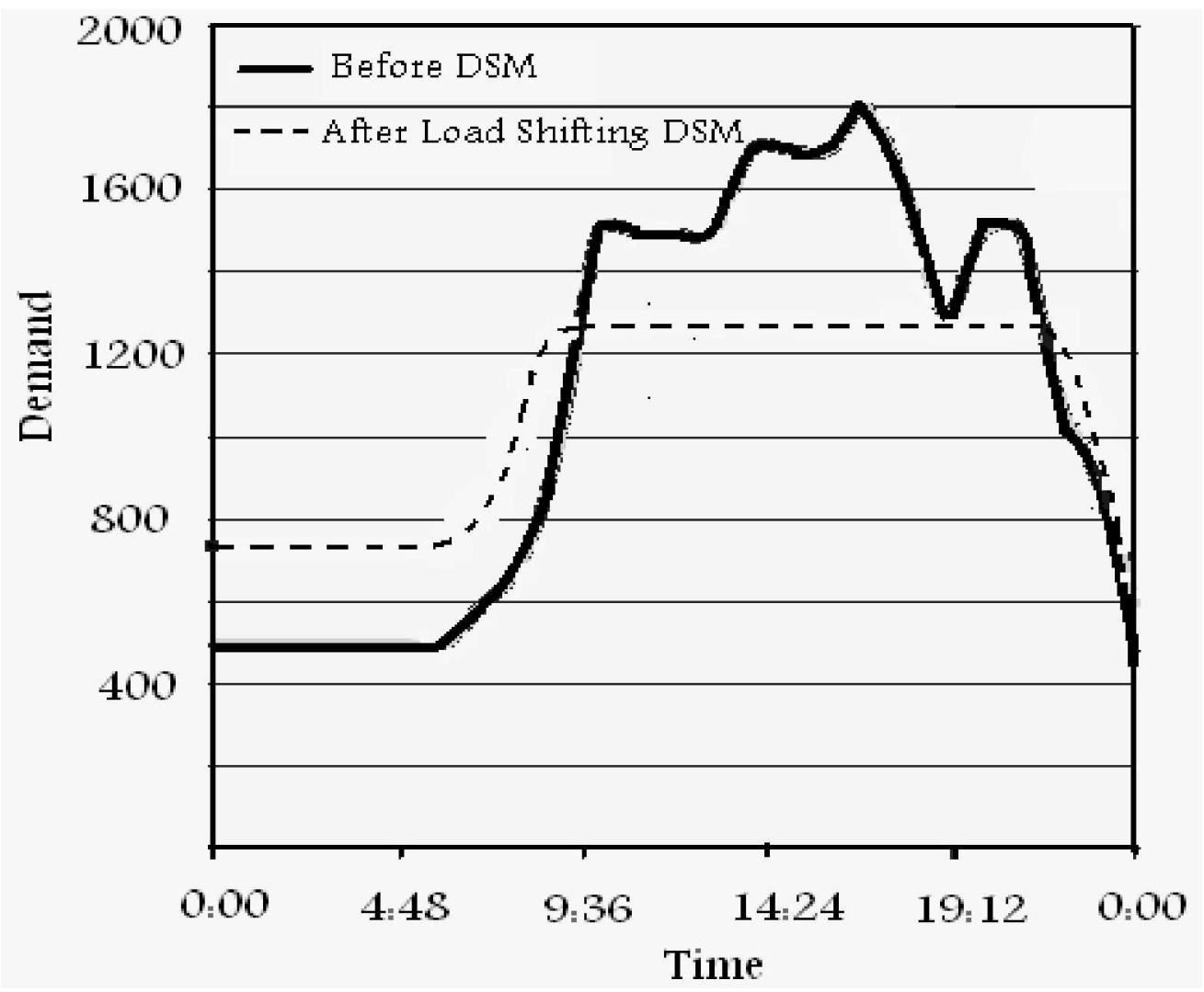

Fig. 8 Load curve after applying load shifting DSM program

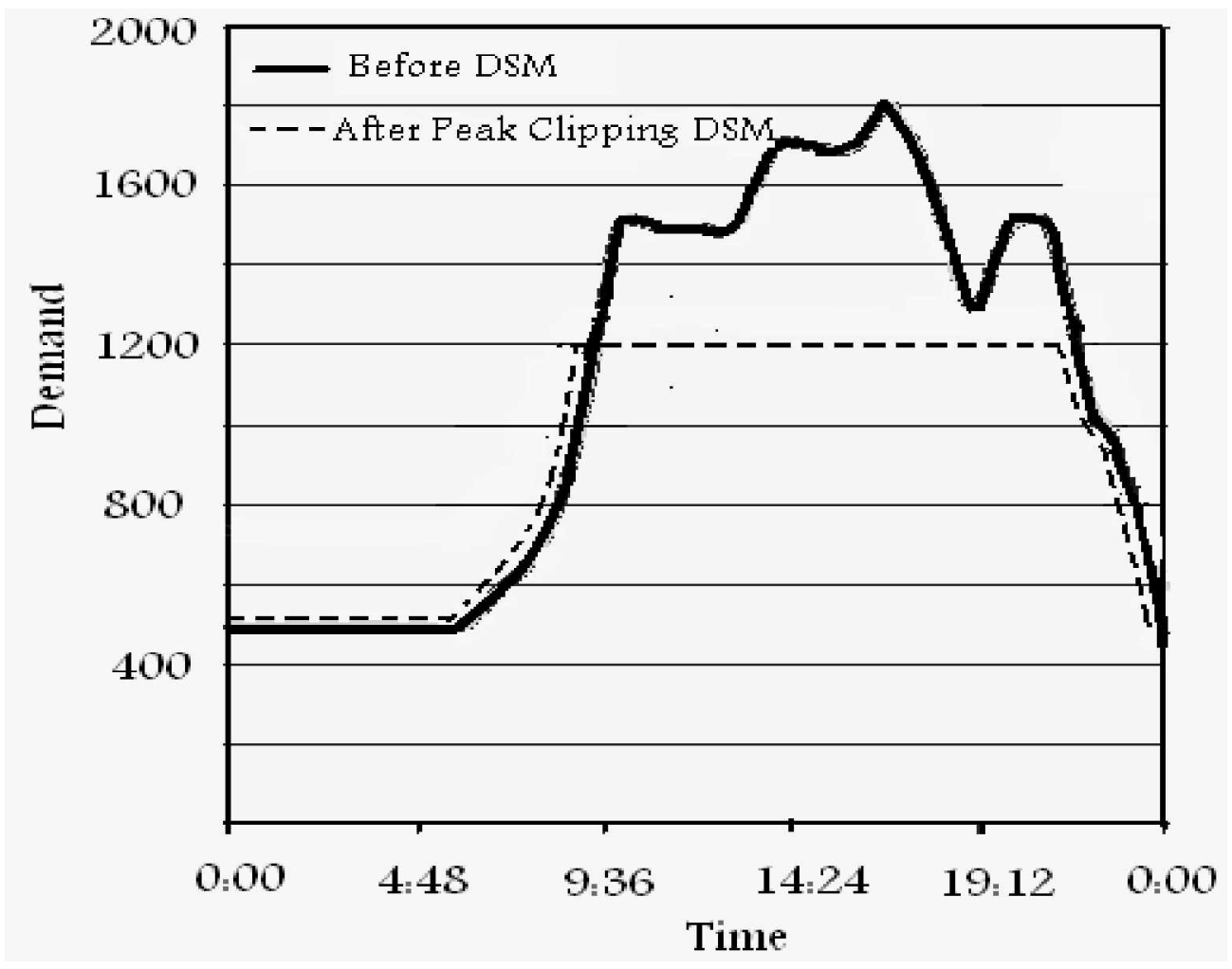

Fig. 9 Load curve after applying peak clipping DSM program 
Table 1 Salient results for an industrial plant when applying load shifting and peak clipping DSM programs and the considered electricity tariff.

\begin{tabular}{|l|c|c|c|}
\hline \multicolumn{1}{|c|}{ Item } & $\begin{array}{c}\text { Before } \\
\text { Applying DSM } \\
\text { Programs }\end{array}$ & $\begin{array}{c}\text { After DSM Load } \\
\text { Shift Program }\end{array}$ & $\begin{array}{c}\text { After DSM } \\
\text { Peak Clipping } \\
\text { Program }\end{array}$ \\
\hline P max KW. & 1800 & 1300 & 1200 \\
\hline Energy kwh/ year & 26700 & 26700 & 22300 \\
\hline P average K.W. & 1112.5 & 1112.5 & 929.16 \\
\hline L.F. & 0.618 & 0.8558 & 0.774 \\
\hline Demand cost L.E. & 157680 & 113880 & 105120 \\
\hline $\begin{array}{l}\text { Energy cost / year } \\
\text { L.E. }\end{array}$ & 1495934.25 & 1495934.25 & 1249413.25 \\
\hline Cost / year L.E. & 1653614.25 & 1609814.25 & 1354533.25 \\
\hline Cost / month L.E. & 137801.188 & 134151.188 & 112877.771 \\
\hline $\begin{array}{l}\text { End-user \% age } \\
\text { saving }\end{array}$ & & 2.649 & 18.086 \\
\hline
\end{tabular}

\section{CONCLUSIONS}

A technical formulation and economical feasibility studies for implementing demand side management programs were presented for industrial and residential users. An optimal based formulation was developed through objective functions utilized to find the best solution subject to some constraints that differ according to each DSM Program and the end user activity peculiarities. The proposed formulation has succeeded to achieve one or more advantage of the following :

- Minimizing the system total peak demand.

- Minimizing customer electricity bill.

- Maximizing utility revenue.

- Maximizing overall system load factor.

The introduced optimal based formulation of the DSM programs was applied to a study case for an industrial plant and the results shows a significant decrease in the load factor and, also, a significant decrease in the end-user electricity bill. 


\section{REFERENCES}

1. Elsobki M.S., "DSM Strategy Options - An Optimal Based formulation, Proceedings AUPTDE- CIRED International Symposium, pp. 58-65, 3-6 June, Amman, Jordan, 1996,

2. M.S. El-Sobki (Jr), "Tariff as a Demand Side Management Tool-its Design and Impact in View of Demand Reduction and Energy Savings technologies", Egyptian Ministry of Electricity Report, October, 1997..

3. Lars E., "Industrial Load Control Using Productivity and Product Quality Constraints", Proceedings DA/DSM EUROPE Distribution Tech. Conference, 14-16 Oct. 1997, Amsterdam, Netherlands.

4. Electric Power Research Institute (EPRI), "Principles and Practice of DSM", Report TR-102556, Project \# 2342-16,1993.

5. Gellings C.W. and Chamberlin J.H., "DSM Concepts and Methods", The Fairmont Press, Liburn-Georgia-USA \& India,1993.

6. Elsobki, M.S., Wahadan, S., "A Demand Side Management (DSM) Priority Selection Technique - its Design and Implementation", CIRED, International Conference \& Exhibition on Electricity Distribution, France, Nice, 1999.

7. Gellings, C. W. "The concept of Demand Side Management for Electric Utilities", IEEE, Vol. 73. No. 10, October 1985.

8. USAID project in Egypt \# 263-014.3, "Energy Conservation and Environment Protection", Report Project, Cairo Egypt, 1995.

9. H. Attia et al., "Priority Ranking of Industrial Loads and Application of Demand Side Management (DSM) Technique ", The Eleventh International Middle East Power System Conference El-Minia, Egypt, MEPCON'2006. 